\title{
Effects of Cold Stimulation on Cardiac-Vagal Activation in Healthy Participants: Randomized Controlled Trial
}

Manuela Jungmann, BA, MA, PhD; Shervin Vencatachellum, BSc, MSc; Dimitri Van Ryckeghem, BSc, MSc, PhD; Claus Vögele, BSc, Dipl-Psych, PhD

Institute for Health and Behaviour, Faculty of Language and Literature, Humanities, Arts and Education, University of Luxembourg, Esch-sur-Alzette, Luxembourg

\section{Corresponding Author:}

Manuela Jungmann, BA, MA, PhD

Institute for Health and Behaviour

Faculty of Language and Literature, Humanities, Arts and Education

University of Luxembourg

Campus Belval, Maison des Sciences Humaines

11, Porte des Sciences

Esch-sur-Alzette, 4366

Luxembourg

Phone: 3524666449755

Fax: 3524666449535

Email: manuela.jungmann@uni.lu

\section{Abstract}

Background: The experience of psychological stress has not yet been adequately tackled with digital technology by catering to healthy individuals who wish to reduce their acute stress levels. For the design of digitally mediated solutions, physiological mechanisms need to be investigated that have the potential to induce relaxation with the help of technology. Research has shown that physiological mechanisms embodied in the face and neck regions are effective for diminishing stress-related symptoms. Our study expands on these areas with the design for a wearable in mind. As this study charts new territory in research, it also is a first evaluation of the viability for a wearables concept to reduce stress.

Objective: The objectives of this study were to assess whether (1) heart rate variability would increase and (2) heart rate would decrease during cold stimulation using a thermode device compared with a (nonstimulated) control condition. We expected effects in particular in the neck and cheek regions and less in the forearm area.

Methods: The study was a fully randomized, within-participant design. Volunteer participants were seated in a laboratory chair and tested with cold stimulation on the right side of the body. A thermode was placed on the neck, cheek, and forearm. We recorded and subsequently analyzed participants' electrocardiogram. The cold stimulation was applied in 16-second intervals over 4 trials per testing location. The control condition proceeded exactly like the cold condition, except we manipulated the temperature variable to remain at the baseline temperature. We measured heart rate as interbeat intervals in milliseconds and analyzed root mean square of successive differences to index heart rate variability. We analyzed data using a repeated-measures ANOVA (analysis of variance) approach with 2 repeated-measures factors: body location (neck, cheek, forearm) and condition (cold, control).

Results: Data analysis of 61 participants (after exclusion of outliers) showed a main effect and an interaction effect for body location and for condition, for both heart rate and heart rate variability. The results demonstrate a pattern of cardiovascular reactivity to cold stimulation, suggesting an increase in cardiac-vagal activation. The effect was significant for cold stimulation in the lateral neck area.

Conclusions: The results confirmed our main hypothesis that cold stimulation at the lateral neck region would result in higher heart rate variability and lower heart rate than in the control condition. This sets the stage for further investigations of stress reduction potential in the neck region by developing a wearable prototype that can be used for cold application. Future studies should include a stress condition, test for a range of temperatures and durations, and collect self-report data on perceived stress levels to advance findings. 


\section{KEYWORDS}

cold stimulation; heart rate reduction; lateral neck region; diving reflex; stress reduction; wearable electronic devices; thermode-based stimulation; acute stress; technology for stress relief; vagus nerve stimulation; psychological stress

\section{Introduction}

\section{Background}

Never before in human history have people been exposed to such fast-paced lifestyles as today, where stress penetrates all areas of everyday life. Stress is a central issue in modern life that affects a broad range of people at various ages and in different professions, beyond levels that are believed to be healthy (eg, [1-3]). Some groups are, however, found to be more vulnerable to stress than others. According to the American Psychological Association [1], groups that are consistently struggling with stress are women and parents, but also younger generations (18-35 years old). In particular, younger people report higher stress levels than any other generation and seem to have difficulties coping with stress [4]. Similarly, a pan-European poll conducted with the general European population showed that $51 \%$ of all workers reported that work-related stress was common in their workplace, while $66 \%$ attributed stress to hours worked or workload [2]. Additionally, $77 \%$ of the European population (36 countries) believed that their job-related stress would increase over the next 5 years [3]. The European Commission has noted the severity of the problem and has made stress and stress management a priority area in Europe's health strategy for 2014-2020 under the framework of psychosocial risks [5].

This snapshot of psychological stress shows that higher stress levels are quite common in highly industrialized nations. Although the situational context that causes stress for the individual may differ between people, depending on personality characteristics, personal history, etc, physiological responses to perceived stress (eg, elevated heart rate and increased respiration) are consistent indicators across individual stress experiences. Acute stress stimulates the sympathetic nervous system, resulting in the ergotropic activation of the cardiovascular, endocrine, and immune systems [6-8]. Physiological stress responses are highly adaptive in the short term, but with regular elicitation they may become maladaptive and the individual's activation level turns chronic. Prolonged exposure to stress has been shown to be associated with long-term health consequences that can lead to disease [6-9].

An ever-growing number of individuals are pursuing well-being in their lives by seeking to deploy smart watches and other digital devices in the hope of reaching a better state of health [10]. Wearable devices have been a popular support in social movements that are spearheading physical self-improvement (eg, the quantified self movement [11]). But digitally mediated solutions for stress reduction are rather sparsely forthcoming. Most devices that aim to reduce daily stress experiences track body metrics (eg, heart rate and respiration) and make offline suggestions, such as exercise and meditation, to disengage from stress [12]. As a result, these solutions are limited in their effectiveness because they do not intervene directly at the time of the acute stress experience. They require behavioral changes that, when applied, will lead to stress reduction. Yet behavioral change necessitates a dedicated time investment, which presents a dilemma for individuals who are already struggling with insufficient time in their day $[13,14]$. Not only a time commitment is needed; some of the suggested solutions also require an undisturbed personal space. This is an additional factor that may make these solutions impractical in everyday settings, where most people are involved with ongoing interactions with other individuals, such as at the office or when taking care of children. Hence, there is a market demand for technologies that provide an approach that not only measures stress but also presents an integral, noninvasive, digitally mediated solution to stress reduction. The solution should provide effective results but also fade into the background of the fast-paced lifestyles that most people experience.

We present an initial study investigating a wearable concept for well-being with the prospect of reducing stress as indexed by increased cardiac-vagal activation. The concept presents an integral solution. It measures an individual's stress levels using heart rate and computing heart rate variability, and it comprises the strategic placement of a cold stimulus to counteract physiological stress by increasing cardiac-vagal activation.

This study is a first exploration of the effects of cold stimulation in the neck region on heart rate and heart rate variability under resting conditions. Stimulation of the neck region as location on the body and cold temperature as a stimulus have been investigated in previous research on stress reduction, but in separate contexts and on different grounds, for example, vagus nerve stimulation (VNS) and cold water face immersion (CWFI). To the best of our knowledge, cold stimulation in the neck region has not yet been combined into a single study. As this is the first study to investigate the effects of cold stimulation in the neck area on heart rate variability and heart rate, we focused on parasympathetic nervous system activation to clearly assess any potential for heart rate reduction. We accordingly selected a study design that de-emphasized complexity and favored a conservative approach by testing participants under resting conditions.

\section{The Relationship Between Heart Rate, Heart Rate Variability, and Stress}

Heart rate variability is associated with functions of the regulatory and homeostatic autonomic nervous system, which is a key structure in physiological arousal with its sympathetic and parasympathetic nervous system branches. Heart rate and heart rate variability constitute measures of autonomic function, whereas heart rate variability provides more information on the dynamic modulation between the sympathetic and parasympathetic branches of the autonomic nervous system [15].

Research has also suggested that the brain and the heart are connected bidirectionally due to the efferent outflow from the brain affecting the heart and the afferent outflow from the heart 
affecting the brain $[16,17]$. The vagus nerve is an integral part of this heart-brain system [18], and heart rate-related measures (eg, heart rate variability) can provide valuable information about the functioning of the heart-brain system. Heart rate variability is the fluctuation of the length of heartbeat intervals [19] and has been suggested to represent the ability of the heart to respond to a variety of physiological and environmental stimuli [20,21].

In recent years, perceived stress levels have been known to be closely associated with measures of cardiac autonomic function, such as heart rate and heart rate variability. For example, Uusitalo et al [22] found that chronic, work-related stress was associated with cardiac autonomic function in hospital nurses at work who were tested over the course of 2 days. Collins et al [23] observed similar findings over a period of 48 hours, studying 30 men who experienced job strain in various job settings. Many other studies (eg, [24-26]) recording short-term or long-term electrocardiograms (ECGs) found comparable results, confirming the association between subjective stress and heart rate variability in larger populations. A recent meta-analysis by Kim et al [27] indicated that heart rate variability can serve as a physiological indicator of stress, which substantiates the findings of an earlier meta-analysis by Thayer et al [28].

Heart rate and heart rate variability are reliable, easily recorded and computed measures. They are assumed to be objective measures of psychological health and stress [27,28] and have often been assessed in cardiovascular and stress research [29-33]. It has also been shown that individuals engaging in biofeedback training are able to control heart rate variability and therefore influence their perception of stress and anxiety [34-36].

In the research reported here, low physiological arousal, or relaxation, was associated with low heart rate and high heart rate variability, indicated by predominately parasympathetic nervous system activation. High physiological arousal, such as that caused by the experience of stressors, indicates high heart rate and low heart rate variability with prevailing sympathetic nervous system activation [37-39]. From the perspective of a wearable concept for stress reduction, heart rate measurements and heart rate variability calculations are already implemented in commercial wearable devices such as chest-worn ambulatory heart rate monitors (eg, heart rate chest belts by Polar [40]). The technology of these heart rate monitors is mature; it has been tested for accuracy and robustness (eg, [41-47]) and can be engineered as part of the design of a stress reduction device.

\section{Vagus Nerve Stimulation and the Diving Reflex}

Cardiovascular research has identified physiological mechanisms that promote relaxation in patients with different physiological and psychological disorders. Methods for heart rate reduction are equally of interest to athletes, who need to speed up their return to homeostasis after physical exertion (eg, [48,49]). Various scientific disciplines, such as sports science and the neurosciences, have studied these physiological mechanisms that initiate relaxation, but their relationship and functional purpose in the body have yet to be fully explicated (eg, [50,51]).
The physiological mechanisms involved are predicated on cranial nerves that are responsible for cardiac-vagal activation and are typically located in the facial area and the head and neck regions. The ascending pathways of the cranial nerves, for example the vagus nerve, transmit various interoceptive signals to the brain (eg, temperature, pain, and pressure), and the descending pathways regulate the functioning of inner organs.

VNS and the diving reflex are the most relevant and accessible physiological mechanisms in relation to our wearable concept. VNS has been used for decades as a therapeutic option in refractory epilepsy. As a method, it has been continuously refined so that applications have broadened to wider patient populations addressing, for example, migraine headaches, Alzheimer disease, depression, and treatment-resistant anxiety disorder [51,52]. VNS is applied to counteract sympathetic nervous system activation by increasing activation of the parasympathetic nervous system, which then induces relaxation in the patient. Direct VNS necessitates the surgical implantation of electrodes in the patient's chest region with extensions threaded under the skin that attach to the cervical vagus nerve in the neck region. Through the implant, electrical impulses are delivered to the vagus nerve that lead to activation. Newer medical VNS applications cause fewer side effects than their invasive VNS counterpart because they deliver electrical impulses through the skin. There are two approaches, termed transcutaneous VNS and noninvasive VNS.

These newer applications either stimulate the auricular branch of the vagus nerve on the external ear through an intra-auricular electrode, or they use metal disks to make contact with the skin on the neck for stimulation of the cervical vagus (commercial examples are Nemos [53] and GammaCore [54]). Transcutaneous VNS and noninvasive VNS are officially classified as noninvasive applications; however, all types of VNS devices use low-voltage electrical signals that aim to produce neurological stimulation.

The efficacy of transcutaneous VNS and noninvasive VNS has been analyzed in studies with patients and healthy individuals to better understand the mechanisms involved [55-58]. Still, there are differences between the cervical vagus and its auricular branch, which need to be taken into account when assessing the vagus nerve's overall potential for stress reduction. Nonis et al [59] conducted an experiment with 12 healthy volunteers, comparing noninvasive VNS with transcutaneous VNS applications. In the control condition for each approach, the stimulation was applied to the long muscle of the neck (sternocleidomastoid muscle). Measuring the electrical activity of the brain (somatosensory evoked potential) during stimulations, the researchers found that cervical noninvasive VNS elicited a reproducible response of vagal afferent activation in 11 of the 12 healthy volunteers, whereas stimulation of the auricular branch evoked a comparable response in only 9 of the 12 healthy volunteers. Morphological studies may explain the predominant response of the cervical vagus nerve. Verlinden et al [60] analyzed 11 pairs of cervical vagus nerves and 4 pairs of intracranial vagus nerves with computer software. They found that the right cervical vagus nerve on average had a 1.5 times larger effective surface area than the left vagus nerve. They also showed that the right cervical vagus nerve contained on average 
2 times more tyrosine hydroxylase-positive nerve fibers than the left nerve, which can positively influence stimulation.

These results informed our study design. We justified the placement of the cold stimulus during experimentation on the cervical vagus nerve, choosing the right lateral neck area to maximize the potential for a parasympathetic nervous system response.

The diving reflex in humans has been characterized by a pattern of respiratory, cardiac, and vascular responses. Some researchers believe that the diving reflex's primary role is to ensure survival when diving into water by conserving oxygen, although there is no consensus on this explanation. A potent stimulus to induce the diving reflex is water contact on the forehead, cheek, eyes, and nose. Trigeminal-brainstem-vagal pathways supply these areas, and stimulation inhibits respiration and provokes vasomotor centers and cardiac-vagal motoneurons [61-65].

In particular, the (cold) temperature aspect of water causes superficial cold receptors to be innervated by the ophthalmic branch of the trigeminal nerve, which promotes the cardiac-vagal activity of the diving reflex $[66,67]$. De Oliveira Ottone et al [48] studied 8 active men who exercised at submaximal levels and subsequently underwent a 15 -minute recovery period in a water tank with cold water at $15^{\circ} \mathrm{C}$, and hot water at $28^{\circ} \mathrm{C}$ and $38^{\circ} \mathrm{C}$. The results indicated that CWFI accelerates while hot water immersion blunts postexercise parasympathetic activation.

Cold water immersion may also be effective at short time intervals. Buchheit et al [68] reported that cold water immersion for 5 minutes at $14^{\circ} \mathrm{C}$ after 10 male cyclists performed submaximal aerobic fitness exercise produced faster parasympathetic reactivation than the control condition. Heindl et al [69] studied the effects of ice cubes on heart rate and blood pressure in 9 healthy volunteers who self-administered the stimulus on forehead, hand, and nasal cavities at 2.5-minute intervals alternated with a 10-minute rest. The bronchial system was also cooled down via cold air at $-25^{\circ} \mathrm{C}$. Heart rate was significantly reduced only during cooling of the nasal cavities and forehead. In sum, cold stimulation applied in short intervals is a promising candidate for parasympathetic activation, and we incorporated it into our study design.

The diving reflex was previously assumed to be strongly linked to breath holding, but recent research suggested otherwise. Kinoshita et al [70] conducted an experiment with 8 healthy volunteers to observe the effects of CWFI and warm water face immersion with and without breathing on heart rate and heart rate variability. The results showed that CWFI diminished cardiac output and increased vagal activity independent of change in body position caused by bending over a basin and unrelated to breath holding. The findings on breath holding confirmed earlier research by Hayashi et al [71], who tested 15 healthy volunteers in 12 trials over 2 days on CWFI with and without breathing. The researchers found that the diving reflex without breath holding increased heart rate variability significantly, indicating that CWFI alone increases vagal activity.

Based on the reviewed research outcomes, we investigated the effects of cold stimulation of the right lateral neck region using a thermode instrument. Control body locations selected for the study were the cheek and forearm. We chose the cheek region because it is central to the diving reflex, and we expected our results to reflect activation of the diving reflex. As the forearm has no known sympathetic or parasympathetic innervation, we did not expect any changes to heart rate or heart rate variability from baseline.

Potential mechanisms underlying any effects of cold stimulation in the neck region are difficult to predict because, in both cranial nerves (vagus and trigeminal nerves), signal relay involves the brainstem regions that indirectly or directly influence the neurochemistry of large areas in the central nervous system [72].

\section{Objective}

Noninvasive VNS is a medical procedure that reduces stress symptoms by lowering heart rate and increasing heart rate variability in patients with serious illnesses. This is achieved through low-voltage electrical impulses sent to the cervical vagus nerve. However, when addressing the general public, the use of electrical impulses as a preventive measure for acute stress is not a viable option without medical supervision.

A safer alternative is cold stimulation, which has been used elsewhere to trigger relaxation (eg, $[48,49,67,68,70,71])$. The overall aim of this project was to design a technique that is effective as a relief strategy for acute stress and can be deployed by otherwise healthy individuals. The technique combines the placement of the stimulus along the cervical vagus (informed by noninvasive VNS) with cold stimulation (referenced from research on the diving reflex).

The objective of this study was to address the following hypotheses: (1) that cold stimulation of the neck and cheek (but not the forearm) should result in higher heart rate variability than in the (nonstimulation) control condition, and (2) that cold stimulation of the neck and cheek (but not the forearm) should result in decreased heart rate compared with the (nonstimulation) control condition.

\section{Methods}

\section{Recruitment}

Participants were 71 healthy volunteers (43 female), with a mean age of 26.8 years (SD 8.57). Volunteers were university students and staff from Luxembourg University. Exclusion criteria were self-reported chronic physical and mental health conditions (eg, bronchial asthma, cardiovascular disorders, depression) or current acute illnesses (eg, flu) and medication intake with known effects on autonomic nervous system function. We further excluded participants with addictions (eg, alcohol, nicotine), as well as pregnant women. We assessed participants' health status via a telephone interview prior to the study. All participants gave informed consent at the start of the study, which was approved by the university's Ethics Review Panel. On completion of the study, participants were compensated for their time and effort in the form of gift vouchers $(€ 10)$. 


\section{Study Design}

The design was a fully randomized, within-participant study. Participants were presented consecutively with cold and neutral stimuli through a thermode device (PATHWAY Model ATS Pathway System, Medoc Ltd, Ramat Yishai, Israel) on 3 body locations (neck, cheek, and forearm). The order of presentation was counterbalanced over participants (see Figure 1), resulting in 6 configurations (see Table 1). Each participant followed the same configuration order throughout the experimental blocks. An experimental block is defined as 3 sessions, 1 for each body location (neck, cheek, and forearm). Each participant engaged in 2 experimental blocks (cold stimulus and control condition), whereby the order of the blocks was counterbalanced from one participant to the next. A total of 35 participants received the cold stimulus condition first followed by the control condition, and 36 participants completed the study in inverse order. Participants individually attended a single experimental session at the university's psychophysiology laboratory. Prior to the main study, we conducted a pilot study with 18 participants.

\section{Calibration Phase}

During the calibration phase, we assessed cold sensitivity by determining whether the preselected temperatures were appropriate for the individual participants (see Figure 1 and Figure 2). Final temperatures were scaled by age and gender and adjusted after a pilot study with 18 participants. During the pilot sessions, we used the temperatures indicated in Table 2. Cold temperatures were determined by corroborating indexes from pain studies (eg, [73]) and studies on postexercise recovery experiments using CWFI (eg, [49,68]). After collecting all the data from the pilot sample, we adapted the temperatures on the basis of participants' input (see Table 3). Among the participants in the pilot sample, 7 considered the temperatures too cold. We then made adjustments to accommodate a larger number of participants and to ensure that temperatures were perceived as not unpleasant. During the calibration period, we marked thermode positions on the participant's skin to ensure that the placements remained identical when repeating trials.

Figure 1. Schematic breakdown of the experiment: each session consisted of four 16-second trials at one body location and 16 seconds at baseline temperature after each trial. The duration of baseline and recovery periods was 3 minutes, and the rest period (pause) between experimental blocks was 5 minutes.

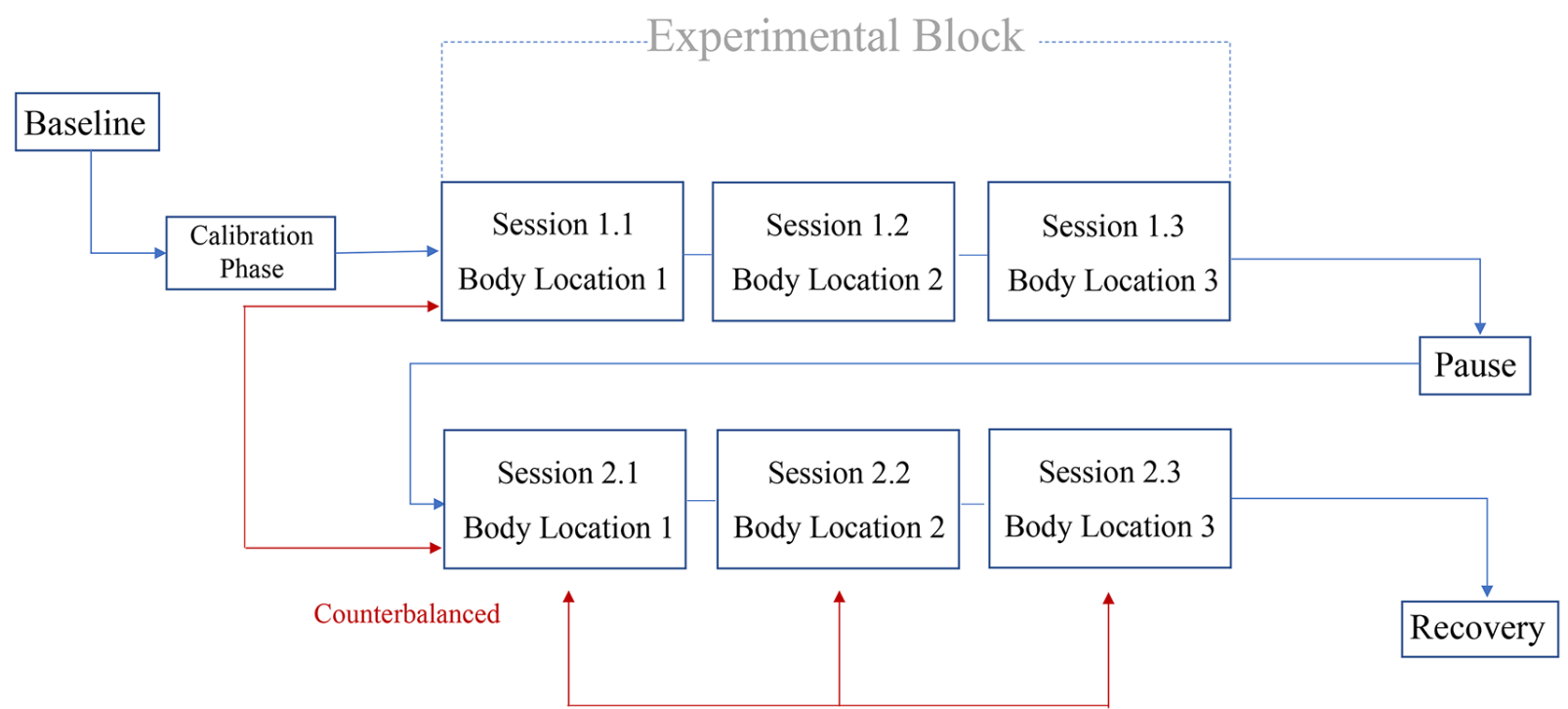

Table 1. Order configurations for cold stimulus and the control condition on neck, cheek, and forearm. Assignment of orders was randomized.

\begin{tabular}{ll}
\hline Applied configurations & Sequence of stimulus on body locations \\
\hline 1 & Cheek, neck, forearm \\
2 & Cheek, forearm, neck \\
3 & Neck, forearm, cheek \\
4 & Neck, cheek, forearm \\
5 & Forearm, neck, cheek \\
6 & Forearm, cheek, neck \\
\hline
\end{tabular}


Figure 2. Thermode head used for stimulus application during the sessions. Cold is transmitted only via the $3 \times 3-\mathrm{cm}$ surface (dark red) of the head.

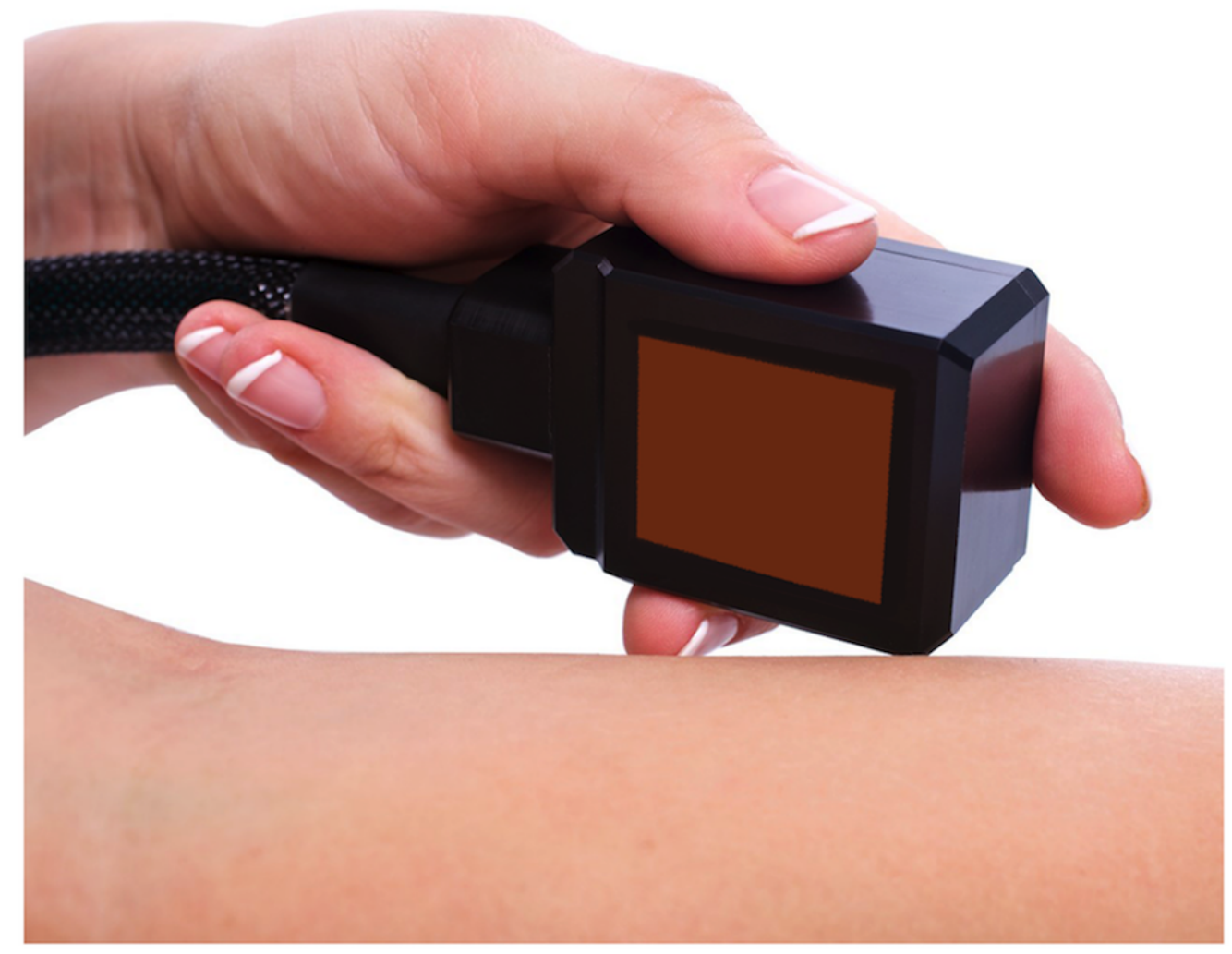

Table 2. Initial temperature ranges used for participants $(\mathrm{N}=18)$ in the pilot sessions.

\begin{tabular}{llc}
\hline Group by age and body location & \multicolumn{2}{c}{ Temperature by gender $\left({ }^{\circ} \mathrm{C}\right)$} \\
& Female $(\mathrm{n}=14)$ & Male $(\mathrm{n}=4)$ \\
\hline Adults $<\mathbf{4 0}$ years old & & 16 \\
$\quad$ Cheek & 16 & 13 \\
Neck & 14 & 10 \\
Forearm & & 9 \\
Adults $>\mathbf{4 0}$ years old & 10 & 9 \\
Cheek & 10 & 5 \\
Neck & 8 & 5 \\
Forearm & & 9 \\
\hline
\end{tabular}


Table 3. Adjusted temperature ranges used for participants $(\mathrm{N}=71)$ of the main sample during the experimental sessions.

\begin{tabular}{|c|c|c|}
\hline \multirow[t]{2}{*}{ Group by age and body location } & \multicolumn{2}{|c|}{ Temperature by gender $\left({ }^{\circ} \mathrm{C}\right)$} \\
\hline & Female $(n=43)$ & Male $(n=28)$ \\
\hline \multicolumn{3}{|l|}{ Adults $<40$ years old } \\
\hline Cheek & 18 & 17 \\
\hline Neck & 19 & 18 \\
\hline Forearm & 18 & 17 \\
\hline \multicolumn{3}{|l|}{ Adults $>\mathbf{4 0}$ years old } \\
\hline Cheek & 18 & 16 \\
\hline Neck & 19 & 17 \\
\hline Forearm & 18 & 16 \\
\hline
\end{tabular}

\section{Stimulus Application}

The experimental block consisted of 3 sessions with 4 trials at 1 body location, adding up to 24 trials for the entire course of the study. Each set of 12 trials comprised either the cold stimulus or control conditions for the neck, cheek, and forearm. Trials carried out in the control condition used the baseline temperature of $31^{\circ} \mathrm{C}$ during the thermode application. The control condition proceeded in identical manner to the cold stimulation. Any differences in responses were therefore due to temperature stimulation and not, for example, tactile stimulation due to the thermode being placed onto the skin.

Stimulus duration was 16 seconds in total and consisted of a 3 -second ramp-up period from baseline $\left(31^{\circ} \mathrm{C}\right)$, a 10 -second leveling-off period, and a 3 -second ramp-down period back to baseline (Figure 3). The 16-second stimulus was succeeded by 16 seconds at the baseline temperature of $31^{\circ} \mathrm{C}$. Participants were instructed to focus their gaze on a cross displayed on a computer screen that changed from white to green when the stimulus was active. The sequence of body locations was communicated to the participant via the monitor screen.

\section{Procedure}

On arrival, participants gave informed consent and were generally informed about the upcoming procedure but were not made aware of the research hypothesis. Participants were then led into a separate chamber inside the laboratory room, where they were seated in an armchair, facing a computer monitor with a computer mouse within their reach. Transducers were attached in an Einthoven lead-II position for ECG monitoring. A baseline of a 3-minute continuous ECG was recorded under resting conditions. During this time, participants were unattended and instructed to fixate their eyes on a white cross displayed on a computer monitor located in front of them.

After the baseline was recorded, participants started with the first experimental block. To induce cold stimuli, we used a thermode with a $3 \times 3-\mathrm{cm}$ head. All stimulus and control applications were placed only on the right side of the body. Throughout the experimental blocks, 2 research assistants trained in the experimental procedure handled and held the thermode stationary onto the designated places of the participant's body. The research assistants were oblivious to the research hypotheses and to any temperature ranges or shifts in the thermode while holding the device (see Figure 2).

The cold stimulus for the cheek was positioned in the middle of the participant's right cheek. For the cold stimulus on the right lateral neck, we selected a place inside the posterior triangle near the clavicle head. The cold stimulus applied to the forearm was placed on the right outer forearm, halfway between the right hand and elbow.

Between experimental blocks, the participant was moved from the chamber to the main laboratory room where he or she sat down unattended for 5 minutes. Heart rate recording was paused during this time, but electrodes remained attached to the chest region. After the pause, the participant returned to be seated in the chamber, and the study advanced with the second experimental block.

Once the trials of both experimental blocks were completed, a 3 -minute recovery period was recorded. As with the recording of the baseline at the beginning of the study, during the recovery recording, the participant was also left unattended. When the recovery period was completed, the research assistants removed the electrodes and the markings from the participant's body. After being compensated, the participant left the laboratory. Figure 4 depicts the overall timeline of the study procedure.

\section{Data Collection}

\section{Equipment and Materials}

We recorded the participants' ECG at a sampling rate of 256 $\mathrm{Hz}$ using a Biopac MP150 amplifier and data acquisition system with AcqKnowledge software version 5.0 (Biopac Systems, Inc, Goleta, CA, USA). ECG was continuously recorded throughout the experimental blocks, as well as at baseline and during recovery periods. We programmed the experiment in E-prime (Psychology Software Tools, Inc, Sharpsburg, PA, USA), which triggered the Medoc thermode (Figure 2) and presented instructions on a computer screen. The ECG signal was stored on a hard disk. Beat detection and artifact control was performed offline with WinCPRS software (Absolute Aliens Oy, Turku, Finland). 
Figure 3. Schematic depiction of the thermode's temperature change during stimulus application.

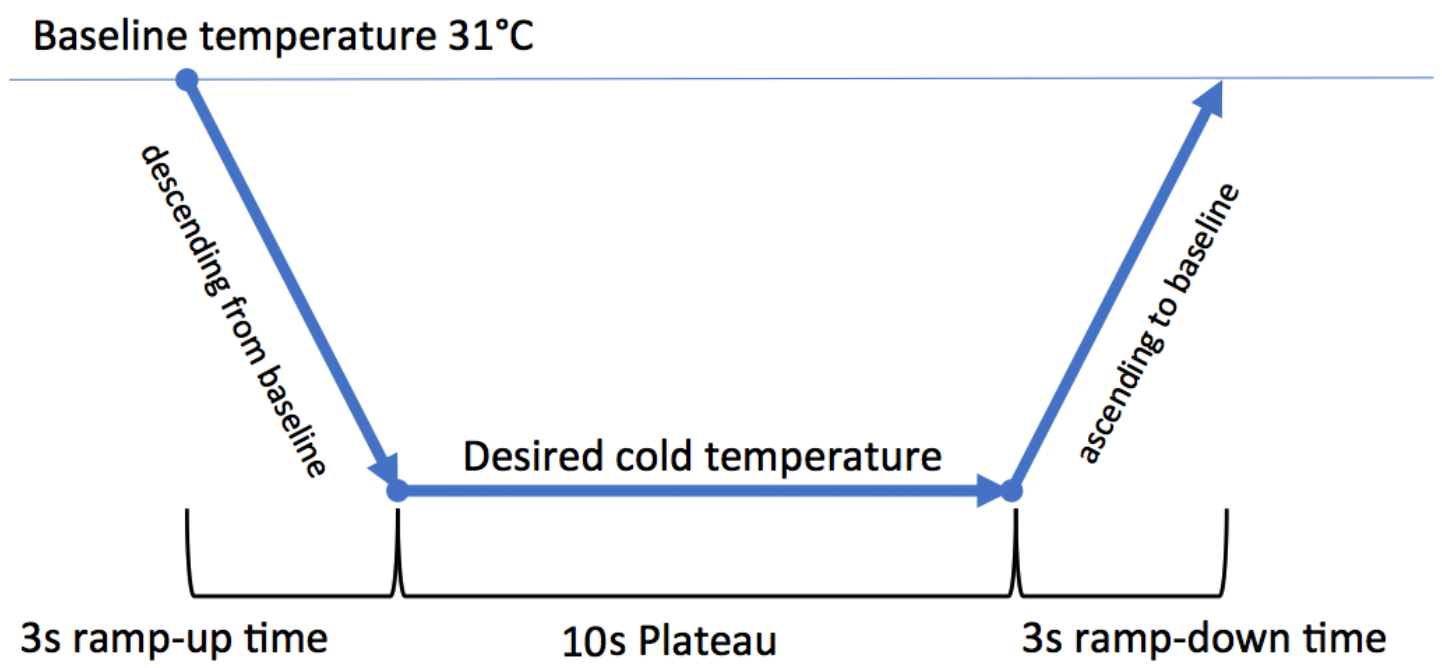

Figure 4. Timeline for the randomized controlled trial. The duration of the experimental blocks and the pause was calculated at 20-25 minutes to compensate for the time of thermode placement on the different body areas and for restabilization of the electrocardiographic signal.

Time (min)

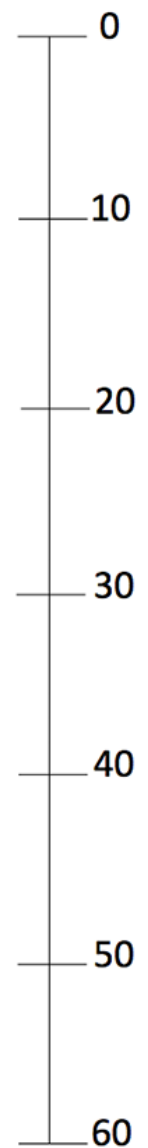

- Participant signs informed consent.

- Provide general information about the study.

- Seat participant in chamber and attach electrodes

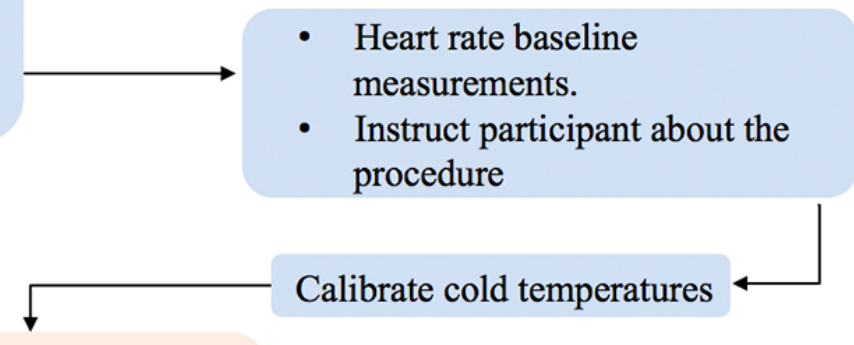

0

$1^{\mathrm{ST}}$ Experimental Block

0

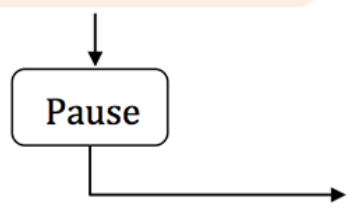

$2^{\text {nd }}$ Experimental Block

The R-wave peak was detected automatically and was followed by a manual correction step where QRS complexes in some cases were not detected by the automatic algorithm and we had to set it manually. We based the automatic R-wave peak detection on application of a distribution-related threshold criterion that we adjusted individually for each participant. As the data showed no ectopic beats or arrhythmia, no other artifact

control was necessary. Time domain measures were directly calculated from R-R interval series.

\section{Data Reduction and Statistical Analysis}

We expressed heart rate as interbeat intervals (IBIs) measured in milliseconds. We separately averaged IBIs from baseline, cold stimulus, and control condition trials, as well as recovery 
values. We analyzed heart rate variability from the IBI in ultrashort-term heart rate variability analysis. The time intervals had a duration of 64 seconds, each comprising $4 \times 16$ seconds per body region (neck, cheek, and forearm). We analyzed heart rate variability using WinCPRS.

As the heart rate variability index, we used the root mean square of successive differences (rMSSD), which is the standard time domain measure for detecting autonomic nervous system activation, in particular parasympathetic activity in short-term measurements.

rMSSD is correlated with the vagus-mediated components of heart rate variability [74] and has better statistical properties than other metrics, such as the proportion of the number of successive $\mathrm{N}-\mathrm{N}$ intervals that differ by more than 50 milliseconds divided by the total number of N-N intervals [75]. rMSSD has been found to be the most reliable metric for ultrashort-term heart rate variability analysis, especially for 10-second intervals under resting conditions [76-80]. We excluded as outliers rMSSD and IBI data with more than 3 SD above the mean for each possible combination of location and condition, reducing the sample included in the analysis to $n=61$.

We analyzed data using a repeated-measures ANOVA (analysis of variance) approach with 2 within-participant factors: body location (neck, cheek, forearm) and condition (cold, control). We conducted follow-up pairwise comparisons using paired $t$ tests, with the Sidak method used to correct for multiple comparisons. All statistical analyses were carried out with IBM SPSS 24 Statistics (IBM Corporation).

\section{Results}

\section{Sample}

The participants' ages ranged from 19 to 51 (mean 26.8, SD 8.57) years. Age was nonnormally distributed with a skewness of 1.16 (SE 0.28) and kurtosis of 0.40 (SE 0.56). Women accounted for $60 \%$ of the sample.

\section{Heart Rate Variability}

A first exploration of the rMSSD data showed skewness and kurtosis in the ranges of 1.71 (SE 0.28) to 2.63 (SE 0.28) and 2.01 (SE 0.56) to 8.26 (SE 0.56), respectively, indicating deviations from the normal distribution. To normalize data, we transformed the data using log transformation (log base 10).
A $2 \times 3$ ANOVA on rMSSD with condition-by-body-location trials (cold and control condition at neck, cheek, and forearm) as within-participant factors revealed a main effect for condition $\left(F_{1,60}=14.68, P<.001, \eta_{\mathrm{p}}{ }^{2}=.20\right)$, demonstrating that heart rate variability across body locations differed significantly between conditions. Throughout the stimulation sites, heart rate variability was significantly higher during cold stimulation (mean 1.04, SD $0.25 \mathrm{~ms}$ ) than in the control stimulation (mean 1.01 , SD $0.24 \mathrm{~ms}$ ). Furthermore, the main effect for body location was marginally significant $\left(F_{2,120}=2.52, P=.08\right.$, $\left.\eta_{\mathrm{p}}{ }^{2}=.04\right)$. Pairwise comparisons indicated that heart rate variability at the neck (mean $1.03, \mathrm{SD} 0.25 \mathrm{~ms}$ ) was marginally higher than at the forearm (mean 1.01, SD $0.25 \mathrm{~ms}$ ) stimulation site $(P=.07)$. No other comparison was significant.

The interaction effect for condition and body location was also significant $\left(F_{2,120}=21.37, P<.001, \eta_{\mathrm{p}}{ }^{2}=.26\right)$. Follow-up $t$ tests showed that the experimental and control conditions differed only for neck and cheek, but not for forearm. Cold stimulation on the neck led to higher heart rate variability (mean 1.07, SD $0.26 \mathrm{~ms}$ ) than in the control condition (mean 1.00, SD $0.25 \mathrm{~ms}$; $t_{60}=6.24, P<.001$ ). On the cheek, cold stimulation induced higher heart rate variability (mean 1.04 , SD $0.25 \mathrm{~ms}$ ) than in the control condition (mean 1.01, SD $0.24 \mathrm{~ms} ; t_{60}=2.88, P=.006$ ). There was no appreciable difference between cold (mean 1.01, SD $0.26 \mathrm{~ms}$ ) and control (mean 1.02, SD $0.25 \mathrm{~ms}$ ) stimulations for the forearm $\left(t_{60}=-1.15, P=.26\right)$. Figure 5 shows the interaction effect [81].

\section{Heart Rate}

We computed a $2 \times 3$ repeated measures ANOVA on IBI with condition (cold and control) and body location (cheek, neck, and forearm) as within-participant factors. This analysis revealed significant main effects for condition $\left(F_{1,60}=9.84, P<.01\right.$, $\left.\eta_{\mathrm{p}}{ }^{2}=.14\right)$ and for body location $\left(F_{2,120}=7.79, P<.001, \eta_{\mathrm{p}}{ }^{2}=.14\right)$. Pairwise comparisons showed significantly longer IBIs in response to stimulation in the neck (mean 912.84, SD 146.69 $\mathrm{ms}$ ) than in the cheek (mean 905.46, SD $145.06 \mathrm{~ms} ; P=.04$ ) region. Similarly, stimulation in the neck area also resulted in longer IBIs than in the forearm (mean 898.87, SD 145.81; $P=.002)$. There was no discernable difference in IBIs between cheek and forearm stimulation sites $(P=.24)$. The findings, illustrated in Figure 6, show that stimulation in the lateral neck region engendered the lowest heart rate. 
Figure 5. Normalized root mean square of successive differences (rMSSD) of all body locations for cold stimulus and control conditions ( $\mathrm{n}=61$ ). The error bars depict within-participant standard error following Cousineau-Morey corrections [81].

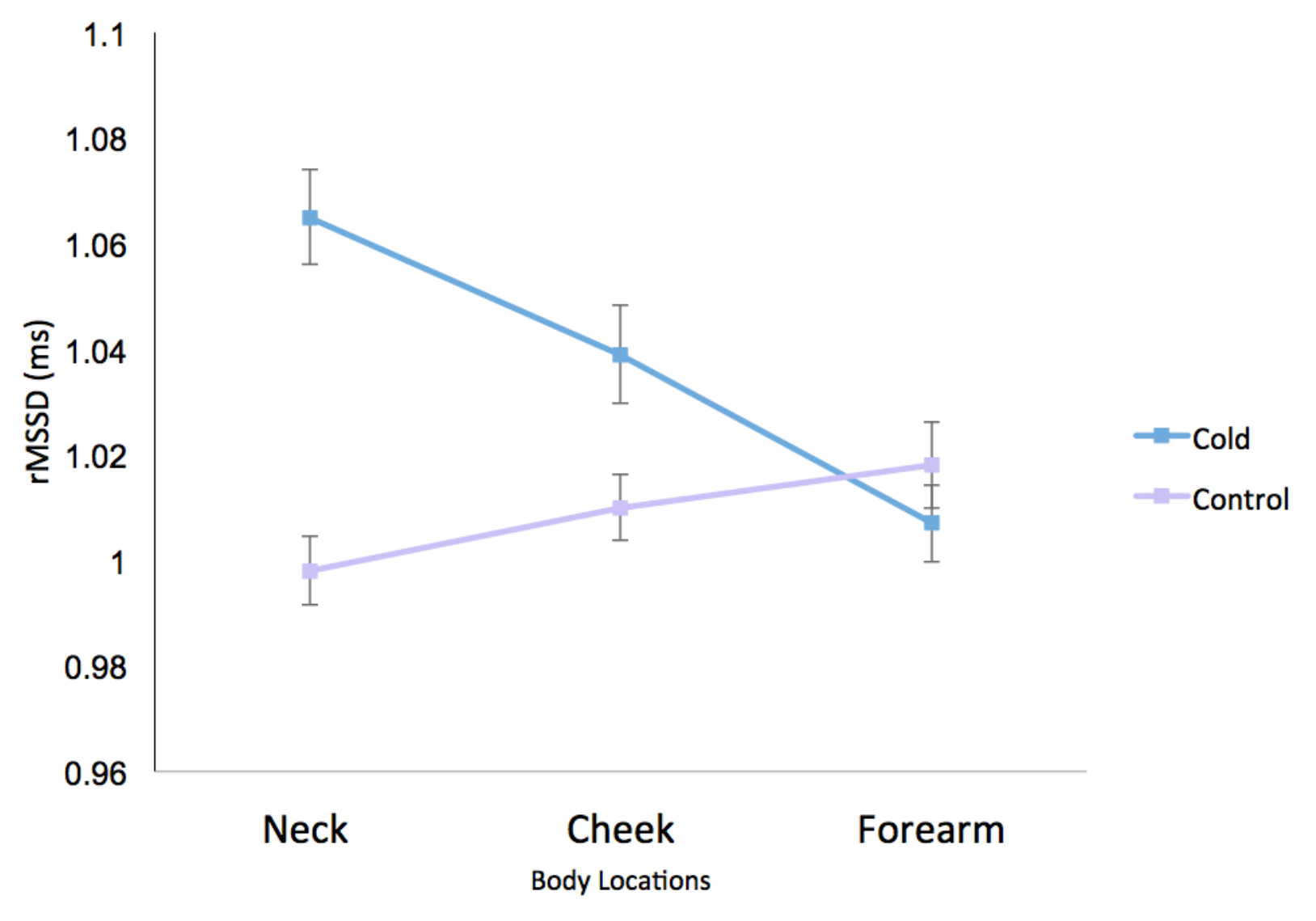

Figure 6. Mean interbeat intervals (IBIs) of all body locations for cold stimulus and control conditions ( $\mathrm{n}=61)$. The error bars depict within-participant standard error following Cousineau-Morey corrections [81].

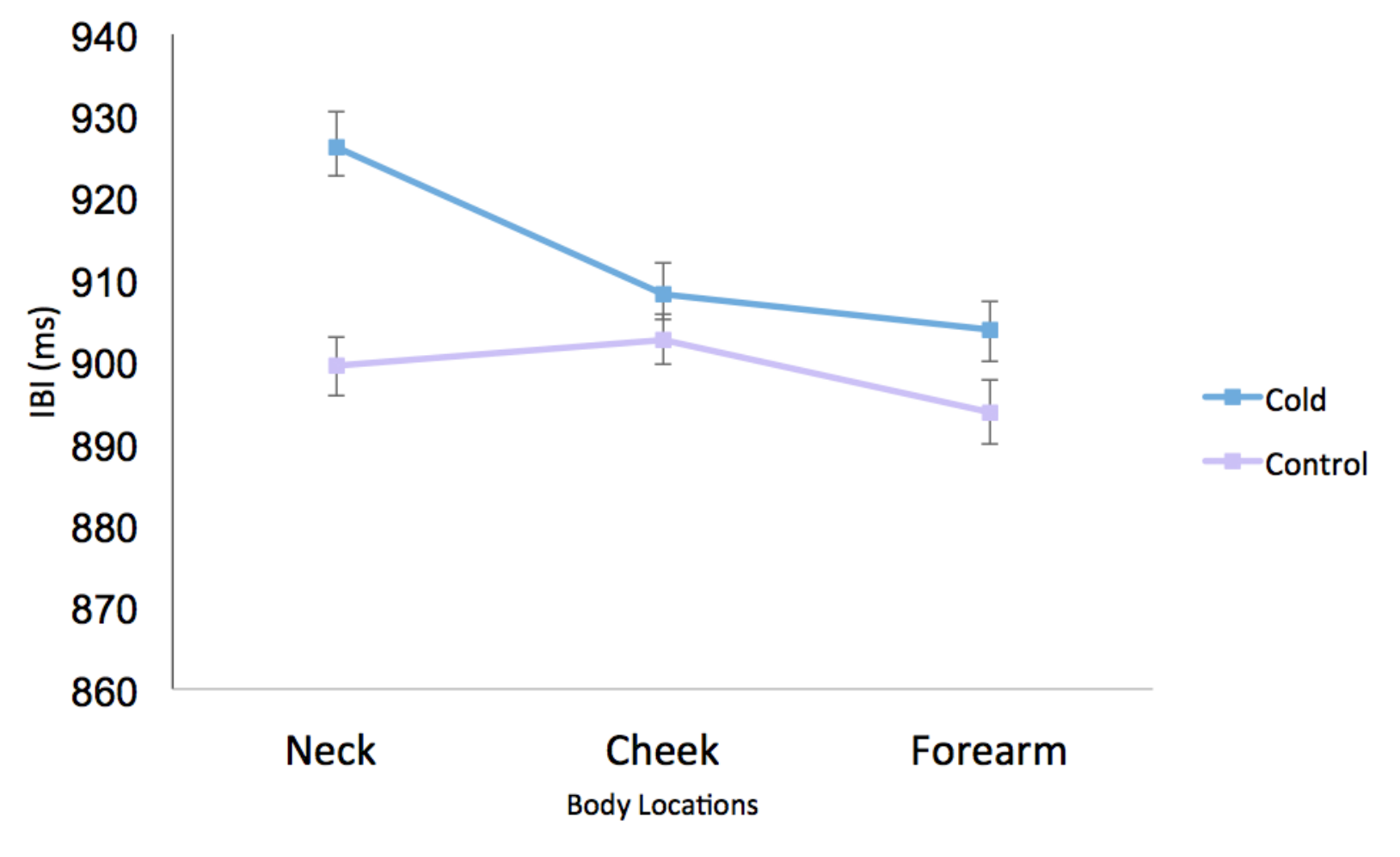


There was also a significant condition-by-body-location interaction effect $\left(F_{2,120}=9.76, P<.001, \eta_{\mathrm{p}}{ }^{2}=.14\right)$. As Figure 6 shows, IBIs were longest - that is, heart rate was lowest—during cold stimulation in the neck region (mean 926.25, SD 153.29 $\mathrm{ms}$ ), as opposed to the control condition (mean 899.43, SD $\left.143.74 \mathrm{~ms} ; t_{60}=4.42, P<.001\right)$.

For the forearm stimulation site, IBIs were slightly longer in the cold (mean 903.97, SD $149.14 \mathrm{~ms}$ ) than in the control condition (mean 893.83, SD $144.82 \mathrm{~ms} ; t_{60}=2.12, P=.04$ ). There were no distinguishable differences in IBIs between the cold (mean 908.23, SD $149.38 \mathrm{~ms}$ ) and the control (mean 902.7, SD $143.54 \mathrm{~ms})$ conditions for the cheek region $\left(t_{60}=1.06, P=.29\right)$.

The overall findings of the study confirmed our main hypothesis that cold stimulation at the lateral neck region would result in higher heart rate variability and lower heart rate than in the control condition.

\section{Discussion}

\section{Principal Results}

This study was motivated by the need for technological support that is effective in reducing acute stress levels in otherwise healthy individuals. With this study, we carried out a first empirical evaluation of the effects of cold stimulation in the lateral neck region on heart rate variability and heart rate. This is an initial step toward assessing the viability of a wearable concept for stress reduction and contributes to the body of basic experimental research conducted toward understanding the effects of temperature stimuli on heart rate and heart rate variability at various body regions. The study design was conservative in that we investigated heart rate reduction and cardiac-vagal activation under resting conditions. To chart this new research territory, which was informed by the combined knowledge from studies in VNS and CWFI, we selected a within-participant approach to collect physiological data in an experimental laboratory setting.

We hypothesized that cold stimulation in the lateral neck and cheek regions would induce higher heart rate variability than in the (nonstimulation) control condition, except for the forearm. Our results confirmed that cold stimulation in the right lateral neck and the cheek areas increases heart rate variability, denoted by higher rMSSD values. These outcomes are in line with previous cold stimulation paradigms, such as CWFI research (eg, [48,49,67,70,71]), which have been shown to modulate parasympathetic activation similar to that observed in the diving reflex. As there have been no previous studies testing for the effects of cold administered to the neck, our findings suggest that the area sensitive to cold potentially extends from the cheek to the neck. Alternatively, cold stimulation in the neck area may have triggered physiological mechanisms known to have an impact in noninvasive VNS. Future studies are needed to investigate the exact physiology underpinning the effects of cold stimulation in the right lateral neck region.

Our hypothesis on heart rate outcomes was only partially supported. Overall, the results showed a pattern of cardiovascular reactivity to cold stimulation as expected; however, we observed this effect only for the neck, but not for the cheek. The heart rate findings regarding the right lateral neck area replicated those observed with heart rate variability. This suggests that cold stimulation in the right lateral neck region has the potential as an effective alternative to electrical impulsing used in VNS interventions.

Unexpectedly, we did not observe any differences in heart rate between the cold and control conditions in the cheek region. Previous research investigating the effects of cold stimulation on heart rate predominately focused on using heart rate variability and the time constant heart rate recovery as postexercise outcome measures (eg, [49,68]). It is consequently difficult to infer from related research the reason behind this contrast in findings.

\section{Limitations}

While the results of our study are promising, there are also limitations. First, the skewed age distribution limits the generalizability of the study's results. Future studies should strive for an even spread of age when recruiting participants. From the perspective of the wearable, it will be important to confirm the effects of cold stimulation across the whole age range, including the elderly population, because this will determine which market should be targeted for commercialization.

Second, we appropriated a medical device (the thermode) for cold application during the study. It had to be handheld by 2 research assistants at the prespecified location of the participant's body. Prolonged holding of the thermode may have caused shifts in pressure across body locations and experimental blocks. However, we aimed to minimize any effects by using the counterbalanced study design. Outcomes may have also been influenced by the close physical proximity of the 2 researchers to the participant. However, the distance between research assistants and participants was consistent across experimental blocks.

Third, although a sampling rate of $256 \mathrm{~Hz}$ for ECG data collection is a well-established standard in the field (cf $[75,82]$ ), future studies may consider using a higher sampling rate to increase the temporal accuracy of heartbeat detection.

\section{Future Consideration}

For this study design, we purposefully omitted a stress condition to perform a first evaluation of the effects of cold stimulation in the lateral neck region on heart rate variability and heart rate. To continue the evaluation, subsequent studies should include a stressor in the study design. A stressor, such as the Trier Social Stress Test, which requires the participant to give a speech in front of a disapproving panel and perform an arithmetic task, would be an effective choice and the next logical step in the evaluation procedure. A follow-up study should also investigate the relationship between heart rate and rMSSD with regard to age and gender by recruiting participants within a wider age bracket.

It would also be advantageous for the continued evaluation to gain insight into the participant's experience of the cold stimulation. However, we based our choice to exclude self-report 
ratings in this study on the fact that requesting participants to fill out ratings on the experience of stress repeatedly during the experimental session would have affected our physiological measurement. A follow-up study should collect self-report data on several dimensions, such as perceived stress, relaxation, and pleasantness levels of the cold stimulation placed on the neck.

Since a wearable solution for stress reduction must stand up to the demands of daily living, a field study that assesses the effects of cold stimulation on heart rate variability and heart rate in the neck region in real-life stress situations also suggests itself as a future investigation. A range of cold temperatures and durations should also be included in future research. However, as a thermode would not be suitable for a field study because it is not mobile and cannot be easily fastened to the neck, the development of a basic prototype is required that can be used for cold application under real-life circumstances.

\section{Conclusion}

Our results demonstrated that cold stimulation in the lateral neck region activates the parasympathetic nervous system in ways that resemble significant research findings in VNS and CWFI. For research, it may be of interest to continue this line of investigation, to broaden the scope of VNS and CWFI, which may expand our understanding of the biological mechanisms that underpin parasympathetic activation. For the development of a wearable for stress reduction, this study's outcomes confirm our hypotheses and substantiate the first step in the evaluation procedure toward the development of a commercial product.

\section{Acknowledgments}

The study was supported by grants from the Institute for Health and Behaviour and the University of Luxembourg. We express our gratitude to Fernand Anton and Marian van der Meulen for their support regarding laboratory facilities and equipment.

\section{Authors' Contributions}

MJ and CV designed the experiment. MJ carried out the experiment. SV assisted during the laboratory experiment. CV, MJ, and SV conducted the statistical analysis. DVR gave input to the statistical analysis. MJ drafted the manuscript. CV revised and commented on the manuscript. SV and DVR contributed to manuscript preparation. All authors approved the final version to be published.

\section{Conflicts of Interest}

None declared.

Editorial Notice: This randomized study was not registered, in possible violation of ICMJE rules for prospective registration of randomized trials. The editor granted an exception because the risk of bias appears low (also due to the within-subject comparisons) and the study was considered formative. However, readers are advised to carefully assess the validity of any potential explicit or implicit claims related to primary outcomes or effectiveness.

\section{References}

1. American Psychological Association. Stress in America: paying with our health. 2015 Feb 4. URL: http://www.apa.org/ news/press/releases/stress/2014/stress-report.pdf [accessed 2018-06-01] [WebCite Cache ID 6zrDakZUm]

2. European Agency for Safety and Health at Work. European opinion poll on occupational safety and health 2013. URL: https://osha.europa.eu/en/surveys-and-statistics-osh/european-opinion-polls-safety-and-health-work/ european-opinion-poll-occupational-safety-and-health-2013 [accessed 2018-06-01] [WebCite Cache ID 6zrEN9PA9]

3. European Agency for Safety and Health at Work. European opinion poll on occupational safety and health 2012. URL: https://osha.europa.eu/en/surveys-and-statistics-osh/european-opinion-polls-safety-and-health-work/ european-opinion-poll-occupational-safety-and-health-2012 [accessed 2018-06-01] [WebCite Cache ID 6zrG04OGf]

4. American Psychological Association. American Psychological Association survey shows teen stress rivals that of adults. 2014 Feb 11. URL: http://www.apa.org/news/press/releases/2014/02/teen-stress.aspx [accessed 2018-06-01] [WebCite Cache ID 6zrGRk0MU]

5. European Commission, Directorate-General for Employment, Social Affairs and Inclusion. Social Agenda, no. 42, 10/2015: A Pathway Back to Work. Catalog no. KE-AF-15-042-EN-C. Brussels, Belgium: European Commission; 2015.

6. Chrousos GP. Stress and disorders of the stress system. Nat Rev Endocrinol 2009 Jul;5(7):374-381. [doi: 10.1038/nrendo.2009.106] [Medline: 19488073]

7. Padgett DA, Glaser R. How stress influences the immune response. Trends Immunol 2003 Aug;24(8):444-448. [Medline: $\underline{12909458]}$

8. Brosschot JF, Gerin W, Thayer JF. The perseverative cognition hypothesis: a review of worry, prolonged stress-related physiological activation, and health. J Psychosom Res 2006 Feb;60(2):113-124. [doi: 10.1016/j.jpsychores.2005.06.074] [Medline: 16439263$]$

9. Cohen S, Tyrrell DA, Smith AP. Psychological stress and susceptibility to the common cold. N Engl J Med 1991 Aug 29;325(9):606-612. [doi: 10.1056/NEJM199108293250903] [Medline: 1713648] 
10. Salamati F, Pasek ZJ. Personal wellness: complex and elusive product and distributed self-services. Procedia CIRP 2014;16:283-288. [doi: 10.1016/j.procir.2014.02.016]

11. Quantified Self Labs. Quantified self: self knowledge through numbers. 2015. URL: http://quantifiedself.com [accessed 2018-06-01] [WebCite Cache ID 6zrGvZwki]

12. Greene S, Thapliyal H, Caban-Holt A. A survey of affective computing for stress detection: evaluating technologies in stress detection for better health. IEEE Consumer Electron Mag 2016 Oct;5(4):44-56. [doi: 10.1109/MCE.2016.2590178]

13. Linke SE, Gallo LC, Norman GJ. Attrition and adherence rates of sustained vs. intermittent exercise interventions. Ann Behav Med 2011 Oct;42(2):197-209 [FREE Full text] [doi: 10.1007/s12160-011-9279-8] [Medline: 21604068]

14. Christensen H, Griffiths KM, Farrer L. Adherence in internet interventions for anxiety and depression. J Med Internet Res 2009;11(2):e13 [FREE Full text] [doi: 10.2196/jmir.1194] [Medline: 19403466]

15. Schubert C, Lambertz M, Nelesen RA, Bardwell W, Choi J, Dimsdale JE. Effects of stress on heart rate complexity--a comparison between short-term and chronic stress. Biol Psychol 2009 Mar;80(3):325-332 [FREE Full text] [doi: 10.1016/j.biopsycho.2008.11.005] [Medline: 19100813]

16. Andreassi J. Psychophysiology: Human Behavior and Physiological Response. Mahwah, NJ: Taylor \& Francis, Inc; 2006.

17. Lacey BC, Lacey JI. Two-way communication between the heart and the brain. Significance of time within the cardiac cycle. Am Psychol 1978 Feb;33(2):99-113. [Medline: 637402]

18. Taggart P, Boyett MR, Logantha S, Lambiase PD. Anger, emotion, and arrhythmias: from brain to heart. Front Physiol 2011;2:67 [FREE Full text] [doi: 10.3389/fphys.2011.00067] [Medline: 22022314]

19. Rajendra AU, Paul JK, Kannathal N, Lim CM, Suri JS. Heart rate variability: a review. Med Biol Eng Comput 2006 Dec;44(12):1031-1051. [doi: 10.1007/s11517-006-0119-0] [Medline: 17111118]

20. Schneiderman N, Ironson G, Siegel SD. Stress and health: psychological, behavioral, and biological determinants. Annu Rev Clin Psychol 2005;1:607-628 [FREE Full text] [doi: 10.1146/annurev.clinpsy.1.102803.144141] [Medline: 17716101]

21. Laborde S, Mosley E, Thayer JF. Heart rate variability and cardiac vagal tone in psychophysiological research recommendations for experiment planning, data analysis, and data reporting. Front Psychol 2017;8:213 [FREE Full text] [doi: 10.3389/fpsyg.2017.00213] [Medline: 28265249]

22. Uusitalo A, Mets T, Martinmäki K, Mauno S, Kinnunen U, Rusko H. Heart rate variability related to effort at work. Appl Ergon 2011 Nov;42(6):830-838. [doi: 10.1016/j.apergo.2011.01.005] [Medline: 21356531]

23. Collins SM, Karasek RA, Costas K. Job strain and autonomic indices of cardiovascular disease risk. Am J Ind Med 2005 Sep;48(3):182-193. [doi: 10.1002/ajim.20204] [Medline: 16094616]

24. Zanstra YJ, Schellekens JMH, Schaap C, Kooistra L. Vagal and sympathetic activity in burnouts during a mentally demanding workday. Psychosom Med 2006;68(4):583-590. [doi: 10.1097/01.psy.0000228012.38884.49] [Medline: 16868268]

25. Hintsanen M, Elovainio M, Puttonen S, Kivimaki M, Koskinen T, Raitakari OT, et al. Effort-reward imbalance, heart rate, and heart rate variability: the Cardiovascular Risk in Young Finns Study. Int J Behav Med 2007;14(4):202-212. [doi: 10.1007/BF03002994] [Medline: 18001235]

26. Vrijkotte TG, van Doornen LJ, de Geus EJ. Effects of work stress on ambulatory blood pressure, heart rate, and heart rate variability. Hypertension 2000 Apr;35(4):880-886. [Medline: 10775555]

27. Kim H, Cheon E, Bai D, Lee YH, Koo B. Stress and heart rate variability: a meta-analysis and review of the literature. Psychiatry Investig 2018 Mar;15(3):235-245 [FREE Full text] [doi: 10.30773/pi.2017.08.17] [Medline: 29486547]

28. Thayer JF, Ahs F, Fredrikson M, Sollers JJ, Wager TD. A meta-analysis of heart rate variability and neuroimaging studies: implications for heart rate variability as a marker of stress and health. Neurosci Biobehav Rev 2012 Feb;36(2):747-756. [doi: 10.1016/j.neubiorev.2011.11.009] [Medline: 22178086]

29. Johnston DW, Tuomisto MT, Patching GR. The relationship between cardiac reactivity in the laboratory and in real life. Health Psychol 2008 Jan;27(1):34-42. [doi: 10.1037/0278-6133.27.1.34] [Medline: 18230011]

30. Appelhans BM, Luecken LJ. Heart rate variability as an index of regulated emotional responding. Rev Gen Psychol 2006;10(3):229-240. [doi: 10.1037/1089-2680.10.3.229]

31. Maeder MT. Heart rate recovery in obstructive sleep apnea: scientific toy or clinical tool? Sleep Breath 2012 Sep;16(3):593-594. [doi: 10.1007/s11325-011-0550-9] [Medline: 21706287]

32. Steptoe A, Vögele C. Methodology of mental stress testing in cardiovascular research. Circulation 1991 Apr;83(4 Suppl):II14-II24. [Medline: 2009622]

33. Peschel SKV, Feeling NR, Vögele C, Kaess M, Thayer JF, Koenig J. A systematic review on heart rate variability in bulimia nervosa. Neurosci Biobehav Rev 2016 Apr;63:78-97. [doi: 10.1016/j.neubiorev.2016.01.012] [Medline: 26828568]

34. Ratanasiripong P, Ratanasiripong N, Kathalae D. Biofeedback intervention for stress and anxiety among nursing students: a randomized controlled trial. ISRN Nurs 2012;2012:ID 827972. [doi: 10.5402/2012/827972]

35. Henriques G, Keffer S, Abrahamson C, Horst SJ. Exploring the effectiveness of a computer-based heart rate variability biofeedback program in reducing anxiety in college students. Appl Psychophysiol Biofeedback 2011 Jun;36(2):101-112. [doi: 10.1007/s10484-011-9151-4] [Medline: 21533678]

36. Zucker TL, Samuelson KW, Muench F, Greenberg MA, Gevirtz RN. The effects of respiratory sinus arrhythmia biofeedback on heart rate variability and posttraumatic stress disorder symptoms: a pilot study. Appl Psychophysiol Biofeedback 2009 Jun;34(2):135-143. [doi: 10.1007/s10484-009-9085-2] [Medline: 19396540] 
37. Delaney JP, Brodie DA. Effects of short-term psychological stress on the time and frequency domains of heart-rate variability. Percept Mot Skills 2000 Oct;91(2):515-524. [doi: 10.2466/pms.2000.91.2.515] [Medline: 11065312]

38. Dimitriev DA, Saperova EV. [Heart rate variability and blood pressure during mental stress]. Ross Fiziol Zh Im I M Sechenova 2015 Jan;101(1):98-107. [Medline: 25868330]

39. Carney RM, Blumenthal JA, Stein PK, Watkins L, Catellier D, Berkman LF, et al. Depression, heart rate variability, and acute myocardial infarction. Circulation 2001 Oct 23;104(17):2024-2028. [doi: 10.1161/hc4201.097834]

40. Polar Global. Train like a pro. URL: https://www.polar.com/en [accessed 2018-06-01] [WebCite Cache ID 6zrJMuwCs]

41. Goodie JL, Larkin KT, Schauss S. Validation of Polar heart rate monitor for assessing heart rate during physical and mental stress. J Psychophysiol 2000 Jul;14(3):159-164. [doi: 10.1027//0269-8803.14.3.159]

42. Giles D, Draper N, Neil W. Validity of the Polar V800 heart rate monitor to measure RR intervals at rest. Eur J Appl Physiol 2016 Mar;116(3):563-571 [FREE Full text] [doi: 10.1007/s00421-015-3303-9] [Medline: 26708360]

43. Nunan D, Donovan G, Jakovljevic DG, Hodges LD, Sandercock GRH, Brodie DA. Validity and reliability of short-term heart-rate variability from the Polar S810. Med Sci Sports Exerc 2009 Jan;41(1):243-250. [doi: 10.1249/MSS.0b013e318184a4b1] [Medline: 19092682]

44. Weippert M, Kumar M, Kreuzfeld S, Arndt D, Rieger A, Stoll R. Comparison of three mobile devices for measuring R-R intervals and heart rate variability: Polar S810i, Suunto t6 and an ambulatory ECG system. Eur J Appl Physiol 2010 Jul;109(4):779-786. [doi: 10.1007/s00421-010-1415-9] [Medline: 20225081]

45. Vanderlei LCM, Silva RA, Pastre CM, Azevedo FM, Godoy MF. Comparison of the Polar S810i monitor and the ECG for the analysis of heart rate variability in the time and frequency domains. Braz J Med Biol Res 2008 Oct;41(10):854-859 [FREE Full text] [Medline: 18853042]

46. Baquero GA, Banchs JE, Ahmed S, Naccarelli GV, Luck JC. Surface 12 lead electrocardiogram recordings using smart phone technology. J Electrocardiol 2015;48(1):1-7. [doi: 10.1016/j.jelectrocard.2014.09.006] [Medline: 25283739]

47. Vezzosi T, Buralli C, Marchesotti F, Porporato F, Tognetti R, Zini E, et al. Diagnostic accuracy of a smartphone electrocardiograph in dogs: comparison with standard 6-lead electrocardiography. Vet J 2016 Oct;216:33-37. [doi: 10.1016/j.tvjl.2016.06.013] [Medline: 27687923]

48. de Oliveira Ottone V, de Castro Magalhães F, de Paula F, Avelar NCP, Aguiar PF, da Matta Sampaio PF, et al. The effect of different water immersion temperatures on post-exercise parasympathetic reactivation. PLoS One 2014 Dec;9(12):e113730 [FREE Full text] [doi: 10.1371/journal.pone.0113730] [Medline: 25437181]

49. Al Haddad H, Laursen PB, Ahmaidi S, Buchheit M. Influence of cold water face immersion on post-exercise parasympathetic reactivation. Eur J Appl Physiol 2010 Feb;108(3):599-606. [doi: 10.1007/s00421-009-1253-9] [Medline: 19882167]

50. Yuan H, Silberstein SD. Vagus nerve stimulation and headache. Headache 2017 Apr;57 Suppl 1:29-33. [doi: 10.1111/head.12721] [Medline: 26473407]

51. George MS, Ward HE, Ninan PT, Pollack M, Nahas Z, Anderson B, et al. A pilot study of vagus nerve stimulation (VNS) for treatment-resistant anxiety disorders. Brain Stimul 2008 Apr;1(2):112-121. [doi: 10.1016/j.brs.2008.02.001] [Medline: $\underline{20633378]}$

52. Merrill CA, Jonsson MAG, Minthon L, Ejnell H, C-son SH, Blennow K, et al. Vagus nerve stimulation in patients with Alzheimer's disease: additional follow-up results of a pilot study through 1 year. J Clin Psychiatry 2006 Aug;67(8):1171-1178. [Medline: $\underline{16965193}$ ]

53. cerbomed. Nemos: for the treatment of epilepsies. 2017. URL: http://www.cerbomed.de/en [accessed 2018-02-28] [WebCite Cache ID 6xZ6tECRy]

54. electroCore. gammaCore. URL: http://gammacore.co.uk [accessed 2018-02-28] [WebCite Cache ID 6xZ7L4MnL]

55. Silberstein SD, Mechtler LL, Kudrow DB, Calhoun AH, McClure C, Saper JR, ACT1 Study Group. Non-invasive vagus nerve stimulation for the acute treatment of cluster headache: findings from the randomized, double - blind, sham - controlled ACT1 study. Headache 2016 Sep;56(8):1317-1332 [FREE Full text] [doi: 10.1111/head.12896] [Medline: 27593728]

56. Grazzi L, Egeo G, Calhoun AH, McClure CK, Liebler E, Barbanti P. Non-invasive vagus nerve stimulation (nVNS) as mini-prophylaxis for menstrual/menstrually related migraine: an open-label study. J Headache Pain 2016 Dec;17(1):91 [FREE Full text] [doi: 10.1186/s10194-016-0684-z] [Medline: 27699586]

57. Frangos E, Komisaruk BR. Access to vagal projections via cutaneous electrical stimulation of the neck: fMRI evidence in healthy humans. Brain Stimul 2017 Jan;10(1):19-27. [doi: 10.1016/j.brs.2016.10.008] [Medline: 28104084]

58. Clancy JA, Mary DA, Witte KK, Greenwood JP, Deuchars SA, Deuchars J. Non-invasive vagus nerve stimulation in healthy humans reduces sympathetic nerve activity. Brain Stimul 2014 Nov;7(6):871-877. [doi: 10.1016/j.brs.2014.07.031] [Medline: 25164906]

59. Nonis R, D'Ostilio K, Schoenen J, Magis D. Evidence of activation of vagal afferents by non-invasive vagus nerve stimulation: an electrophysiological study in healthy volunteers. Cephalalgia 2017 Nov;37(13):1285-1293 [FREE Full text] [doi: 10.1177/0333102417717470] [Medline: 28648089]

60. Verlinden TJM, Rijkers K, Hoogland G, Herrler A. Morphology of the human cervical vagus nerve: implications for vagus nerve stimulation treatment. Acta Neurol Scand 2016 Mar;133(3):173-182. [doi: 10.1111/ane.12462] [Medline: 26190515]

61. Schuitema K, Holm B. The role of different facial areas in eliciting human diving bradycardia. Acta Physiol Scand 1988 Jan;132(1):119-120. [doi: 10.1111/j.1748-1716.1988.tb08306.x] [Medline: 3223302] 
62. De Burgh Daly M. Peripheral Arterial Chemoreceptors and Respiratory-Cardiovascular Integration. Oxford, UK: Oxford University Press; 1997.

63. Elsner R, Gooden B. Diving and asphyxia. A comparative study of animals and man. Monogr Physiol Soc 1983;40:1-168. [Medline: $\underline{6685226]}$

64. Khurana RK, Watabiki S, Hebel JR, Toro R, Nelson E. Cold face test in the assessment of trigeminal-brainstem-vagal function in humans. Ann Neurol 1980 Feb;7(2):144-149. [doi: 10.1002/ana.410070209] [Medline: 7369721]

65. Blix AS, Folkow B. Cardiovascular adjustments to diving in mammals and birds. Compr Physiol 2011;Jan(suppl 8):917-945. [doi: 10.1002/cphy.cp020325]

66. Eckberg DL, Mohanty SK, Raczkowska M. Trigeminal-baroreceptor reflex interactions modulate human cardiac vagal efferent activity. J Physiol 1984 Feb;347:75-83 [FREE Full text] [Medline: 6707976]

67. Kawakami Y, Natelson BH, DuBois AR. Cardiovascular effects of face immersion and factors affecting diving reflex in man. J Appl Physiol 1967 Dec;23(6):964-970. [doi: 10.1152/jappl.1967.23.6.964] [Medline: 6065071]

68. Buchheit M, Peiffer JJ, Abbiss CR, Laursen PB. Effect of cold water immersion on postexercise parasympathetic reactivation. Am J Physiol Heart Circ Physiol 2009 Feb;296(2):H421-H427 [FREE Full text] [doi: 10.1152/ajpheart.01017.2008] [Medline: 19074671$]$

69. Heindl S, Struck J, Wellhöner P, Sayk F, Dodt C. Effect of facial cooling and cold air inhalation on sympathetic nerve activity in men. Respir Physiol Neurobiol 2004 Aug 20;142(1):69-80. [doi: 10.1016/j.resp.2004.05.004] [Medline: 15351305]

70. Kinoshita T, Nagata S, Baba R, Kohmoto T, Iwagaki S. Cold-water face immersion per se elicits cardiac parasympathetic activity. Circ J 2006 Jun;70(6):773-776 [FREE Full text] [Medline: 16723802]

71. Hayashi N, Ishihara M, Tanaka A, Osumi T, Yoshida T. Face immersion increases vagal activity as assessed by heart rate variability. Eur J Appl Physiol Occup Physiol 1997 Oct;76(5):394-399. [doi: 10.1007/s004210050267] [Medline: 9367278]

72. Fanselow EE. Central mechanisms of cranial nerve stimulation for epilepsy. Surg Neurol Int 2012;3(Suppl 4):S247-S254 [FREE Full text] [doi: 10.4103/2152-7806.103014] [Medline: 23230529]

73. Pfau DB, Krumova EK, Treede R, Baron R, Toelle T, Birklein F, et al. Quantitative sensory testing in the German Research Network on Neuropathic Pain (DFNS): reference data for the trunk and application in patients with chronic postherpetic neuralgia. Pain 2014 May;155(5):1002-1015. [doi: 10.1016/j.pain.2014.02.004] [Medline: 24525274]

74. Stein PK, Bosner MS, Kleiger RE, Conger BM. Heart rate variability: a measure of cardiac autonomic tone. Am Heart J 1994 May;127(5):1376-1381. [Medline: 8172068]

75. Task Force of the European Society of Cardiology and the North American Society of Pacing and Electrophysiology. Heart rate variability: standards of measurement, physiological interpretation and clinical use. Circulation 1996 Mar 01;93(5):1043-1065 [FREE Full text] [Medline: 8598068]

76. Nussinovitch U, Elishkevitz KP, Katz K, Nussinovitch M, Segev S, Volovitz B, et al. Reliability of utra-short ECG indices for heart rate variability. Ann Noninvasive Electrocardiol 2011 Apr;16(2):117-122. [doi: 10.1111/j.1542-474X.2011.00417.x] [Medline: 21496161]

77. McNames J, Aboy M. Reliability and accuracy of heart rate variability metrics versus ECG segment duration. Med Biol Eng Comput 2006 Sep;44(9):747-756. [doi: 10.1007/s11517-006-0097-2] [Medline: 16960742]

78. Salahuddin L, Cho J, Jeong MG, Kim D. Ultra short term analysis of heart rate variability for monitoring mental stress in mobile settings. Conf Proc IEEE Eng Med Biol Soc 2007;2007:4656-4659. [doi: 10.1109/IEMBS.2007.4353378] [Medline: $\underline{18003044]}$

79. Schroeder EB, Whitsel EA, Evans GW, Prineas RJ, Chambless LE, Heiss G. Repeatability of heart rate variability measures. J Electrocardiol 2004 Jul;37(3):163-172. [Medline: 15286929]

80. Munoz ML, van Roon A, Riese H, Thio C, Oostenbroek E, Westrik I, et al. Validity of (ultra-)short recordings for heart rate variability measurements. PLoS One 2015;10(9):e0138921 [FREE Full text] [doi: 10.1371/journal.pone.0138921] [Medline: 26414314]

81. O'Brien F, Cousineau D. Representing error bars in within-subject designs in typical software packages. Quant Methods Psychol 2014 Apr 01;10(1):56-67. [doi: 10.20982/tqmp.10.1.p056]

82. Ellis RJ, Zhu B, Koenig J, Thayer JF, Wang Y. A careful look at ECG sampling frequency and R-peak interpolation on short-term measures of heart rate variability. Physiol Meas 2015 Sep;36(9):1827-1852. [doi: 10.1088/0967-3334/36/9/1827] [Medline: 26234196]

\section{Abbreviations}

ANOVA: analysis of variance

CWFI: cold water face immersion

ECG: electrocardiogram

IBI: interbeat interval

rMSSD: root mean square of successive differences

VNS: vagus nerve stimulation 
Edited by G Eysenbach; submitted 28.02.18; peer-reviewed by U Ebner-Priemer, M Lang, J Pietilä; comments to author 22.03.18; revised version received 14.06.18; accepted 28.07.18; published 09.10.18

Please cite as:

Jungmann M, Vencatachellum S, Van Ryckeghem D, Vögele C

Effects of Cold Stimulation on Cardiac-Vagal Activation in Healthy Participants: Randomized Controlled Trial

JMIR Formativ Res 2018;2(2):e10257

URL: http://formative.jmir.org/2018/2/e10257/

doi: $10.2196 / 10257$

PMID: 30684416

CManuela Jungmann, Shervin Vencatachellum, Dimitri Van Ryckeghem, Claus Vögele. Originally published in JMIR Formative Research (http://formative.jmir.org), 09.10.2018. This is an open-access article distributed under the terms of the Creative Commons Attribution License (https://creativecommons.org/licenses/by/4.0/), which permits unrestricted use, distribution, and reproduction in any medium, provided the original work, first published in JMIR Formative Research, is properly cited. The complete bibliographic information, a link to the original publication on http://formative.jmir.org, as well as this copyright and license information must be included. 